\title{
Precipitating Factors for Hospitalization with Heart Failure: Prevalence and Clinical Impact Observations from the Gulf CARE (Gulf aCute heArt failuRe rEgistry)
}

\author{
Amar M. Salam ${ }^{a}$ b Kadhim Sulaiman ${ }^{c}$ Alawi A. Alsheikh-Alid, e Rajvir Singh ${ }^{f}$ \\ Khalid F. AlHabib ${ }^{g}$ Ibrahim Al-Zakwani ${ }^{\text {h }}$ Nidal Asaad $^{\text {a }} \quad$ Awad Al-Qahtani $^{\text {a }}$ Mohammed \\ Al-Jarallahi Wael AlMahmeed ${ }^{j}$ Bassam Bulbanat ${ }^{i}$ Mustafa Ridhak ${ }^{k}$ Nooshin Bazargani ${ }^{1}$ \\ Haitham Amin ${ }^{m}$ Ahmed Al-Motarreb ${ }^{n}$ Prashanth Panduranga ${ }^{c}$ Husam AlFaleh ${ }^{\circ}$ \\ Abdulla Shehab $^{p}$ Jassim Al Suwaidi ${ }^{\text {b }}$ \\ ${ }^{a}$ College of Medicine, Qatar University, Doha, Qatar; ${ }^{b}$ Adult Cardiology, Hamad Medical Corporation, Doha, Qatar; \\ 'Department of Cardiology, Royal Hospital, Muscat, Oman; ${ }^{\mathrm{d} C o l l e g e}$ of Medicine, Mohammed Bin Rashid University

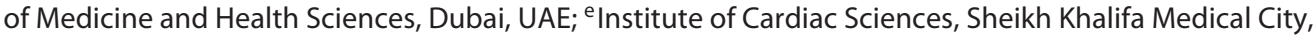

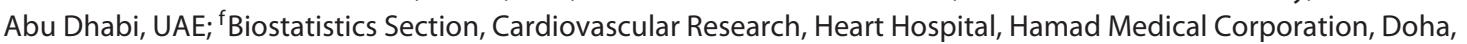 \\ Qatar; ${ }^{9}$ Department of Cardiac Sciences, King Fahad Cardiac Center, King Saud University, Riyadh, Saudi Arabia; \\ h Department of Pharmacology and Clinical Pharmacy, College of Medicine and Health Sciences, Sultan Qaboos \\ University, and Gulf Health Research, Seeb, Oman; 'Department of Cardiology, Sabah Al-Ahmed Cardiac Center, \\ Kuwait, Kuwait; ${ }^{j}$ Cleveland Clinic, Abdu Dhabi, UAE; ${ }^{k}$ Department of Cardiology, Adan Hospital, Kuwait, Kuwait;

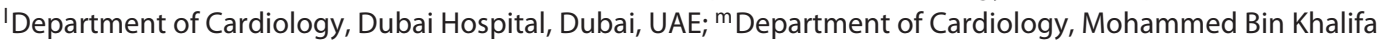 \\ Cardiac Center, Manamah, Bahrain; ' Department of Cardiology, Faculty of Medicine, Sana'a University, Sana'a, \\ Yemen; ${ }^{\circ}$ Department of Cardiology and Cardiovascular Surgery, Security Forces Hospital, Riyadh, Saudi Arabia; \\ ${ }^{\mathrm{P} C o l l e g e}$ of Medicine and Health Sciences, UAE University, AI Ain, UAE
}

\section{Highlights of the Study}

- This is the first large evaluation of the prevalence and impact of precipitating factors for hospitalization of patients with acute heart failure in the Middle East.

- It underlines the urgent need to address noncompliance with medications and ischemic heart disease with preventive and therapeutic interventions to reduce the burden and cost of hospitalizations due to heart failure in our region.

\section{Keywords}

Heart failure $\cdot$ Precipitating factors $\cdot$ Mortality

\begin{abstract}
Objective: Despite the expanding burden of heart failure (HF) worldwide, data on HF precipitating factors (PFs) in developing countries, particularly the Middle East, are very lim-
\end{abstract}

ited. We examined PFs in patients hospitalized with acute HF in a prospective multicenter HF registry from 7 countries in the Middle East. Method: Data were derived from the Gulf

Abstracts from this study were presented in part at the American Heart Association (AHA) Scientific Sessions held 15-19 November 2014, in Chicago, IL, USA, and published in Circulation (vol. 130, issue 22, suppl. 2) on 25 November, 2014.

\begin{tabular}{ll}
\hline KARGER & $\begin{array}{l}\text { Ko 2019 The Author(s) } \\
\text { Published by S. Karger AG, Basel }\end{array}$ \\
karger@argarger.com & This is an Open Access article licensed under the Creative Commons \\
www.karger.com/mpp & $\begin{array}{l}\text { Attribution-NonCommercial-4.0 International License (CC BY-NC) } \\
\text { (http://www.karger.com/Services/OpenAccessLicense), applicable to } \\
\text { the online version of the article only. Usage and distribution for com- } \\
\text { mercial purposes requires written permission. }\end{array}$
\end{tabular}

Amar M. Salam

College of Medicine, Qatar University

PO Box 3050

Doha (Qatar)

E-Mail dramarsalam@yahoo.com 
CARE (Gulf aCute heArt failuRe rEgistry) for a prospective, multinational, multicenter study of consecutive patients hospitalized with HF in 47 hospitals in 7 Middle Eastern countries between February 2012 and November 2012. PFs were determined by the treating physician from a predefined list at the time of hospitalization. Results: The study included 5,005 patients hospitalized with acute HF, 2,276 of whom (45.5\%) were hospitalized with acute new-onset HF (NOHF) and 2,729 of whom (54.5\%) had acute decompensated chronic HF (DCHF). PFs were identified in 4,319 patients (86.3\%). The most common PF in the NOHF group was acute coronary syndromes (ACS) (39.2\%). In the DCHF group, it was noncompliance with medications (27.8\%). Overall, noncompliance with medications was associated with a lower inhospital mortality (OR $0.47 ; 95 \% \mathrm{Cl} 0.28-0.80 ; p=0.005)$ but a higher 1-year mortality (OR 1.43; 95\% Cl 1.1-1.85; $p=$ $0.007)$. ACS was associated with higher inhospital mortality (OR 1.84; 95\% Cl 1.26-2.68; $p=0.002$ ) and higher 1-year mortality (OR 1.62; $95 \% \mathrm{Cl} 1.27-2.06 ; p=0.001)$. Conclusion: Preventive and therapeutic interventions specifically directed at noncompliance with medications and ACS are warranted in our region.

(C) 2019 The Author(s)

Published by S. Karger AG, Basel

\section{Introduction}

Heart failure (HF) is a global pandemic affecting an estimated 26 million people worldwide and resulting in significant mortality, morbidity, and cost of care $[1,2]$. The annual direct costs of HF in the USA alone are projected to increase from USD 20.9 billion in 2012 to USD 53.1 billion in 2030 , with $80 \%$ of these costs of care attributable to hospitalizations [3]. Hospitalization for acute $\mathrm{HF}$ can be due to acute new-onset "de novo" HF (NOHF) and acute decompensated chronic HF (DCHF). A number of factors have been identified as precipitating acute HF hospitalizations [4-11]. These include: myocardial ischemia, nonadherence to medications, arrhythmias, infection, uncontrolled hypertension (HTN), anemia, renal impairment, and diet. Understanding the precipitating factors (PF) that lead to acute HF hospitalizations, particularly those that are avoidable, is of great importance in reducing the HF disease burden and improve outcomes. However, there is a limited number of studies evaluating the prevalence of PF in a realworld acute HF patient population and the implications of different types of common PF on long-term outcomes. In addition, most reported data included either DCHF or a mixture of NOHF and DCHF, but no studies comparing both in terms of PF prevalence and outcomes.

Precipitating Factors in Heart Failure
This study was carried out in a large cohort of patients enrolled in the Gulf CARE (aCute heArt failuRe rEgistry) and was designed to (1) identify the prevalence of PFs in a large real-world cohort of consecutive patients hospitalized with acute HF, (2) differentiate the frequency of different PFs according to the type of acute HF (NOHF or DCHF), and (3) evaluate the impact of PFs on the immediate and 1-year clinical outcomes.

\section{Methods}

\section{Registry Design}

Gulf CARE involved a multicenter, multinational, prospective, observational study that recruited patients admitted with a final diagnosis of acute HF to 47 hospitals in 7 countries in the Arabian Gulf (Oman, Saudi Arabia, UAE, Qatar, Bahrain, Yemen, and Kuwait) between February 2012 and November 2012 [12]. Data were collected on episodes of hospitalization as per a standardized case report form (CRF), beginning at the point of initial care and including each patient's date of discharge, transfer out of hospital, or inhospital death, and for those discharged alive at a 3 - and 12-month follow-up. Each patient was given a unique ID number to prevent double counting. The study was registered at clinicaltrials.gov with the number NCT01467973. Registry design, methodology, and hospital characteristics have been previously described in detail [13].

This study included patients with acute HF of both genders who were $\geq 18$ years old and admitted to the participating hospitals. Acute HF was defined based on the European Society of Cardiology (ESC) definition [14]. Acute HF was further classified as either DCHF or NOHF, also based on ESC guidelines [14]. DCHF was defined as worsening $\mathrm{HF}$ in patients with a previous diagnosis or hospitalization for HF. NOHF was defined as acute HF in patients with no prior history of $\mathrm{HF}$.

Patients were excluded from the study if (1) they were discharged from the emergency room without admission, (2) they were transferred from a nonregistry hospital, (3) they could not provide informed consent, or (4) their final diagnosis was not HF. Registry organization and data collection and validation are outlined in a previous report from the Gulf CARE $[12,13]$. PFs for hospitalization were entered by the treating physician from a predefined list in the CRF at the time of hospitalization. Each patient was assigned 1 major factor that lead to hospitalization. When no factors were clearly identified, this was recorded as "unknown."

Definitions of variables in the CRF were based on the 2008 ESC guidelines and the 2005 American College of Cardiology (ACC) clinical data standards $[14,15]$. Diabetes mellitus (DM) was defined as having a history of diabetes diagnosed and treated with medication and/or insulin, or fasting blood glucose $7.0 \mathrm{mmol} / \mathrm{L}$ $(126 \mathrm{mg} / \mathrm{dL})$, or hemoglobin $(\mathrm{Hb}) \mathrm{A}_{1 \mathrm{c}} \geq 6.5 \%$. HTN was defined as having a history of HTN diagnosed and treated with medication, systolic blood pressure $(\mathrm{BP})>140 \mathrm{~mm} \mathrm{Hg}$ or diastolic $\mathrm{BP}>90 \mathrm{~mm}$ $\mathrm{Hg}$ on at least 2 occasions, or for patients with diabetes or chronic kidney disease (CKD) systolic BP $>130 \mathrm{~mm} \mathrm{Hg}$ or diastolic BP $>80 \mathrm{~mm} \mathrm{Hg}$ on at least 2 occasions. Hyperlipidemia was defined as a history of dyslipidemia diagnosed and/or treated by a physician or total cholesterol $>5.18 \mathrm{mmol} / \mathrm{L}(200 \mathrm{mg} / \mathrm{dL})$, low-density 
lipoprotein cholesterol $\geq 3.37 \mathrm{mmol} / \mathrm{L}$ (130 mg/dL) or high-density lipoprotein cholesterol $<1.04 \mathrm{mmol} / \mathrm{L}(40 \mathrm{mg} / \mathrm{dL})$. Patients smoking cigarettes, a water pipe, or cigars, or chewing tobacco within 1 month of index admission were classified as current smokers. CKD was defined as a glomerular filtration rate (GFR) $<60 \mathrm{~mL} / \mathrm{min} / 1.73 \mathrm{~m}^{2}$ for $\geq 3$ months, with or without kidney damage or on dialysis. If no GFR was available, serum creatinine $>177$ $\mathrm{mmol} / \mathrm{L}$ or $2 \mathrm{mg} / \mathrm{dL}$ was marked as CKD. Obesity was defined as a body mass index $(\mathrm{BMI})>25$. Cardiomyopathy was defined as a myocardial disorder in which the heart muscle is structurally and functionally abnormal (in the absence of coronary artery disease [CAD], HTN, valvular disease, or congenital heart disease) sufficient to cause the observed myocardial abnormality. A definition of infection in the registry was any systemic infection needing antibiotics. The presence of CAD was defined according to a history of CAD, myocardial infarction, or any coronary revascularization procedure including percutaneous coronary intervention (PCI) and coronary artery bypass surgery (CABG).

The primary objective of this study was to identify the rate of each PF in the acute DCHF and NOHF groups. The secondary objective was to identify the inhospital and 1-year outcome associated with different PFs. End points assessed for inhospital outcomes were mortality and length of stay (LOS); end points assessed at 1 year were rehospitalization rates for HF and mortality.

\section{Statistical Analysis}

Baseline and outcome variables were presented as $n$ (\%) for categorical variables, and interval variables were presented as mean and standard deviation (SD) for normally distributed data and median and interquartile range (IQR) for nonnormally distributed variables. The $\chi^{2}$ test or Fisher exact test for $<5$ cells were applied to see if there were associations between the NOHF and DCHF groups regarding categorical variables. The Student $t$ test was used for normally distributed-interval variables and the Wilcoxon rank sum test for nonnormally distributed interval variables. The associations between PFs and mortality (inhospital and 1-year) and PFS and 1-year rehospitalization were examined using multivariate logistic regressions. Adjusted odds ratio (OR) and $95 \%$ confidence interval (CI) were used to quantify the association between baseline variables and mortality. $p<0.05$ (two-tailed) was considered statistically significant. The Statistical Package for the Social Sciences v22.0 (SPSS Inc., USA) was used for the analysis.

\section{Results}

The study included 5,005 patients hospitalized with acute HF, 2,276 of whom (45.5\%) were hospitalized with acute NOHF and 2,729 of whom (54.5\%) were hospitalized with acute DCHF. Overall, PFs for HF hospitalizations were identified in 4,319 patients $(86.3 \%)$ as follows: noncompliance with medications in 964 (19.3\%), noncompliance with diet in $136(2.7 \%)$, acute coronary syndromes (ACS) in 1,365 (27.3\%), uncontrolled HTN in $410(8.2 \%)$, arrhythmia in $301(6.0 \%)$, anemia in 154 (3.1\%), infection in $731(14.6 \%)$, and worsening renal function in 221 (4.4\%).

\section{Baseline Characteristics}

Patients with NOHF were 4 years younger and more likely to be current smokers while patients with DCHF were more likely to have prior systolic left ventricular dysfunction, CAD, valvular heart disease, atrial fibrillation, stroke/transient ischemic attacks, DM, HTN, hyperlipidemia, CKD, asthma/chronic obstructive pulmonary disease (COPD), thyroid disease, and prior revascularization procedures. Patients with NOHF had a higher heart rate, systolic and diastolic BP, and elevated troponins. Patients with DCHF had significantly lower ejection fraction on echocardiography. N-terminal pro-Btype natriuretic peptide levels were similar in the 2 groups (Table 1).

\section{PFs for Hospitalization for $\mathrm{HF}$}

PFs for HF hospitalizations were identified in 1,894 patients in the NOHF group (83.2\%) and in 2,425 in the DCHF group (88.9\%). The most common PF identified in the NOHF group was ACS (39.2\%), followed by infection (11.1\%), and uncontrolled HTN (9.7\%). The most common PF identified in the DCHF group was noncompliance with medications $(27.8 \%)$, followed by infection (17.5\%), and ACS (17.3\%) (Table 1).

\section{Outcomes and Follow-up}

There were no significant differences between the 2 groups regarding inhospital mortality and LOS. At the 1-year follow-up, mortality and rehospitalization for $\mathrm{HF}$ were significantly higher in the DCHF group than in the NOHF group. Revascularization procedures (PCI/ $\mathrm{CABG}$ ) were more common in the NOHF group with no significant differences in coronary angiographic findings (Table 2).

\section{Outcomes according to PFs}

In the NOHF group, the longest LOS was seen in patients with anemia and worsening renal function (8 days for both), followed by arrhythmia and infection (7 days for both). The shortest LOS was seen with HTN and noncompliance with diet (5 days for both).

In the DCHF group, the longest LOS was seen with arrhythmia (9 days), followed by infection (8 days). The shortest LOS was seen with HTN and noncompliance with diet (5 days for both) (Fig. 1a).

\section{Inhospital Mortality}

In the NOHF group, the highest mortality rate was seen with anemia (11.4\%), followed by ACS and infection $(9.9 \%$ for both), while the lowest rate was seen with HTN (1.8\%). 
Table 1. Baseline characteristics

\begin{tabular}{|c|c|c|c|}
\hline & $\begin{array}{l}\text { Acute NOHF } \\
(n=2,276 ; 45.5 \%)\end{array}$ & $\begin{array}{l}\text { Acute DCHF } \\
(n=2,729 ; 54.5 \%)\end{array}$ & $p$ value \\
\hline Age, years & $57 \pm 14.7$ & $61 \pm 15.0$ & $<0.001$ \\
\hline Female sex & $831(36.5)$ & $1,043(38.2)$ & 0.214 \\
\hline \multicolumn{4}{|l|}{ A previous CV history } \\
\hline Known systolic LV dysfunction & $249(10.9)$ & $2,033(74.5)$ & $<0.001$ \\
\hline Known CAD & $690(30.3)$ & $1,647(60.4)$ & $<0.001$ \\
\hline Atrial fibrillation & $145(6.4)$ & $462(16.9)$ & $<0.001$ \\
\hline Valvular heart disease & $176(7.6)$ & $502(18.4)$ & $<0.001$ \\
\hline Congenital heart disease & $18(0.8)$ & $23(0.8)$ & 0.839 \\
\hline PVD & $89(3.9)$ & $134(4.9)$ & 0.088 \\
\hline Stroke/TIA & $126(5.5)$ & $278(10.2)$ & $<0.001$ \\
\hline A family history of cardiomyopathy/HF & $127(5.6)$ & $132(4.8)$ & 0.237 \\
\hline \multicolumn{4}{|l|}{ Other comorbidities } \\
\hline Current smoker & $673(29.6)$ & $430(15.8)$ & $<0.001$ \\
\hline Diabetes mellitus & $1,008(44.3)$ & $1,484(54.4)$ & $<0.001$ \\
\hline Hypertension & $1,239(54.4)$ & $1,820(66.7)$ & $<0.001$ \\
\hline Hyperlipidemia & $619(27.2)$ & $1,180(43.2)$ & $<0.001$ \\
\hline CKD/dialysis & $213(9.4)$ & $531(19.5)$ & $<0.001$ \\
\hline Sleep apnea requiring therapy & $33(1.4)$ & $66(2.4)$ & 0.014 \\
\hline Asthma/COPD & $180(7.9)$ & $321(11.8)$ & $<0.001$ \\
\hline Thyroid disease & $50(2.2)$ & $131(4.8)$ & $<0.001$ \\
\hline \multicolumn{4}{|l|}{ Past cardiac procedures } \\
\hline PCI & $163(7.2)$ & $376(13.8)$ & $<0.001$ \\
\hline CABG & $90(4.0)$ & $276(10.1)$ & $<0.001$ \\
\hline \multicolumn{4}{|l|}{ Clinical and biochemical parameters } \\
\hline Heart rate, bpm & $98.5 \pm 24$ & $95.2 \pm 22.4$ & $<0.001$ \\
\hline Systolic BP, mm Hg & $142 \pm 35.0$ & $133.5 \pm 32.9$ & $<0.001$ \\
\hline Diastolic BP, mm Hg & $84.6 \pm 20.3$ & $78.4 \pm 18.8$ & $<0.001$ \\
\hline Respiratory rate, /min & $24(20-28)$ & $24(20-28)$ & 0.124 \\
\hline BMI & $28.0 \pm 6.0$ & $28.3 \pm 6.5$ & 0.037 \\
\hline NT pro-BNP, pg/mL & $3,236(1,404-6849)$ & $3,127(1,298-7,769)$ & 0.739 \\
\hline Elevated troponin & $1,054(46.3)$ & $848(31.1)$ & $<0.001$ \\
\hline $\mathrm{HbA}_{1 \mathrm{c}}, \%$ & $7.4 \pm 2.3$ & $7.1 \pm 2.2$ & 0.006 \\
\hline Total cholesterol, $\mathrm{mmol} / \mathrm{L}$ & $4.9 \pm 2.0$ & $4.7 \pm 2.5$ & 0.002 \\
\hline Creatinine, $\mu \mathrm{mol} / \mathrm{L}$ & $97(75-124)$ & $106(80-144)$ & $<0.001$ \\
\hline LVEF, \% & $38.6 \pm 13.7$ & $35.5 \pm 14.1$ & $<0.001$ \\
\hline Hemoglobin, g/dL & $13.0(12-15)$ & $12.2(11-14)$ & $<0.001$ \\
\hline \multicolumn{4}{|l|}{ Precipitating factors for developing $\mathrm{HF}$} \\
\hline Noncompliance with medications & $205(9.0)$ & $759(27.8)$ & $<0.001$ \\
\hline Noncompliance with diet & $35(1.5)$ & $101(3.7)$ & $<0.001$ \\
\hline Acute coronary syndromes & $893(39.2)$ & $472(17.3)$ & $<0.001$ \\
\hline Uncontrolled hypertension & $220(9.7)$ & $190(7.0)$ & 0.001 \\
\hline Uncontrolled arrhythmia & $123(5.4)$ & $178(6.5)$ & 0.097 \\
\hline Anemia & $70(3.1)$ & $84(3.1)$ & 0.994 \\
\hline Infection & $253(11.1)$ & $478(17.5)$ & $<0.001$ \\
\hline Worsening renal function & $71(3.1)$ & $150(5.5)$ & $<0.001$ \\
\hline Other causes & $24(1.1)$ & $13(0.5)$ & 0.017 \\
\hline Unknown & $382(16.8)$ & $304(11.1)$ & $<0.001$ \\
\hline
\end{tabular}

Values are expressed as $n(\%)$, mean $\pm \mathrm{SD}$, or median (IQR). NOHF, new-onset heart failure; DCHF, decompensated chronic heart failure; $\mathrm{AF}$, atrial fibrillation; $\mathrm{BP}$, blood pressure; $\mathrm{CAD}$, coronary artery disease; CV, cardiovascular; PVD, peripheral vascular disease; TIA, transient ischemic attack; CKD, chronic kidney disease; COPD, chronic obstructive pulmonary disease; PCI, percutaneous coronary intervention; CABG, coronary artery bypass graft; BMI, body mass index; NT pro-BNP, N-terminal pro-B-type natriuretic peptide; $\mathrm{HbA}_{1 \mathrm{c}}$, glycated hemoglobin; LV, left ventricular; LVEF, left ventricular ejection fraction. 


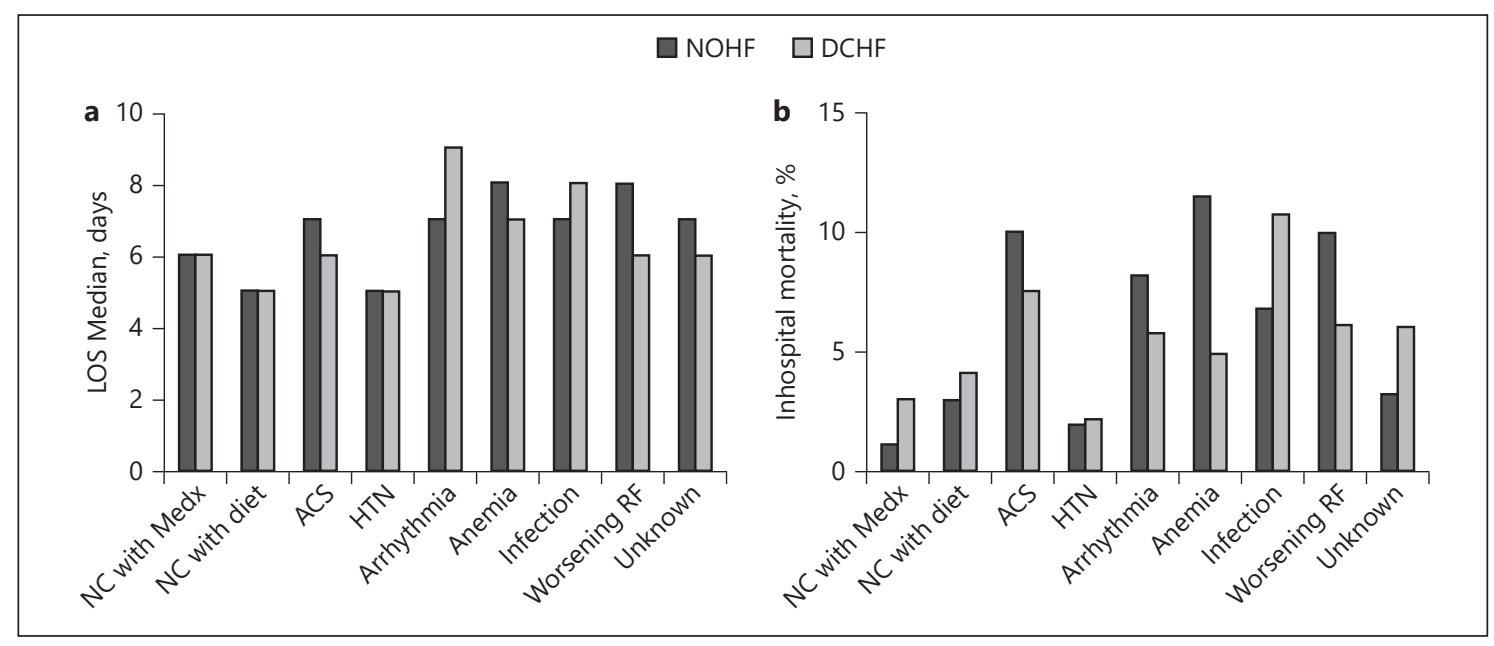

Fig. 1. Inhospital outcomes. a LOS. b Mortality. LOS, length of stay; NC, noncompliance; Medx, medications; ACS, acute coronary syndromes; HTN, hypertension; RF, renal function.

Table 2. Outcomes and follow-up ${ }^{1}$

\begin{tabular}{|c|c|c|c|}
\hline & $\begin{array}{l}\text { Acute NOHF } \\
(n=2,276 ; 45.5 \%)\end{array}$ & $\begin{array}{l}\text { Acute DCHF } \\
(n=2,729 ; 54.5 \%)\end{array}$ & $p$ value \\
\hline \multicolumn{4}{|l|}{ Inhospital outcomes } \\
\hline Median LOS, days (IQR) & $7(4-10)$ & $6(4-11)$ & 0.0897 \\
\hline Mortality & $153(6.7)$ & $160(5.9)$ & 0.211 \\
\hline \multicolumn{4}{|l|}{ 1-Year follow-up } \\
\hline Cumulative mortality & $390(17.1)$ & $622(22.8)$ & $<0.001$ \\
\hline Rehospitalization for $\mathrm{HF}$ & $427(23.8)$ & $648(32.3)$ & $<0.001$ \\
\hline $\mathrm{PCI} / \mathrm{CABG}$ & $209(11.6)$ & $171(8.5)$ & 0.001 \\
\hline
\end{tabular}

Values are expressed as $n(\%)$, unless otherwise indicated. NOHF, new-onset heart failure; DCHF, decompensated chronic heart failure; LOS, length of stay; HF, heart failure; PCI, percutaneous coronary intervention; CABG, coronary artery bypass grafting. ${ }^{1}$ There were missing observations in 75 cases and 313 patients died in hospital.

In the DCHF group, the highest mortality rate was seen with infection (10.7\%), followed by ACS (7.4\%), and worsening renal function $(6 \%)$, while the lowest rate was seen with HTN (2.1\%) (Fig. 1b).

\section{One-Year Mortality}

In the NOHF group, the highest mortality rate was seen with worsening renal function (33.8\%), followed by ACS (20.4\%), and anemia (20\%), while the lowest rate was seen with HTN (9.1\%).

In the DCHF group, the highest mortality rate was seen with infection (28.7\%), followed by worsening renal function (28.7\%), and noncompliance with diet (26.7\%), while the lowest rate was seen with HTN (12.1\%) (Fig. 2a).

\section{Rehospitalization for HF after 1 Year}

In the NOHF group, the highest rehospitalization rate was seen with noncompliance with diet (40\%), followed by anemia $(32.9 \%)$, and arrhythmia (32.5\%), while the lowest rate was seen in patients with ACS (24.7\%).

In the DCHF group, the highest rehospitalization rate was seen in patients with noncompliance with diet (41.6\%), followed by anemia (39.3\%), and HTN (39\%), while the lowest rate was seen in patients with ACS (31.6\%) (Fig. 2b).

\section{Multivariate Analysis}

Multivariable logistic regression analyses showed that noncompliance with medications and HTN were significantly associated with lower inhospital mortality, while 


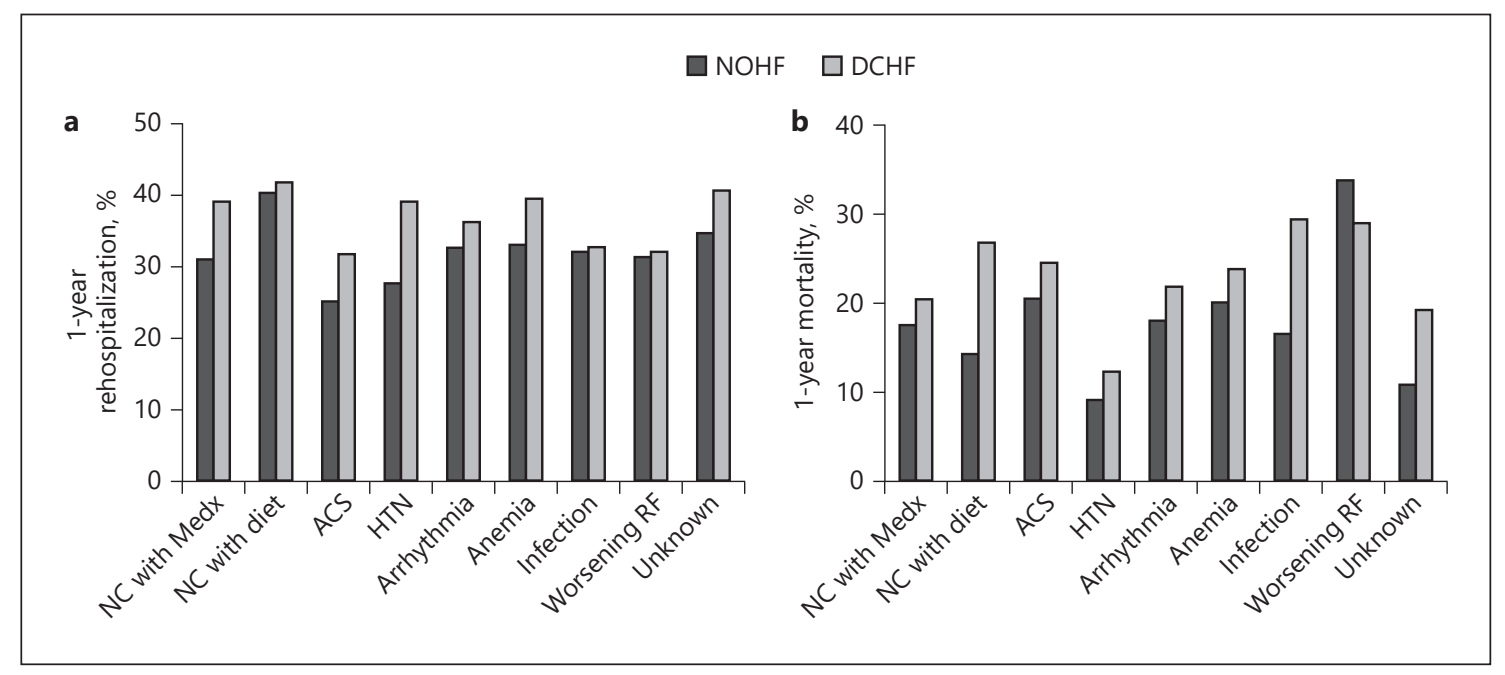

Fig. 2. 1-Year outcomes. a Rehospitalization. b Mortality. NC, noncompliance; Medx, medications; ACS, acute coronary syndromes; HTN, hypertension; RF, renal function.

Table 3. Multivariate logistic regression for inhospital and 1-year mortality and 1-year rehospitalization

\begin{tabular}{|c|c|c|c|}
\hline & Adjusted OR & $95 \%$ CI & $p$ value \\
\hline \multicolumn{4}{|l|}{ Inhospital mortality } \\
\hline Noncompliance with medications & 0.47 & $0.28-0.80$ & 0.005 \\
\hline Noncompliance with diet & 0.71 & $0.27-1.83$ & 0.47 \\
\hline ACS & 1.84 & $1.26-2.68$ & 0.002 \\
\hline HTN & 0.37 & $0.17-0.80$ & 0.01 \\
\hline Arrhythmia & 1.32 & $0.75-2.31$ & 0.33 \\
\hline Anemia & 1.57 & $0.90-3.10$ & 0.19 \\
\hline Infection & 1.90 & $1.26-2.88$ & 0.002 \\
\hline Worsening RF & 1.45 & $0.79-2.66$ & 0.23 \\
\hline \multicolumn{4}{|l|}{ 1-Year mortality } \\
\hline Noncompliance with medications & 1.43 & $1.10-1.85$ & 0.007 \\
\hline Noncompliance with diet & 1.80 & $1.15-2.80$ & 0.01 \\
\hline ACS & 1.62 & $1.27-2.06$ & 0.001 \\
\hline HTN & 0.68 & $0.47-0.99$ & 0.05 \\
\hline Arrhythmia & 1.56 & $1.04-2.09$ & 0.03 \\
\hline Anemia & 1.65 & $1.07-2.54$ & 0.02 \\
\hline Infection & 1.93 & $1.50-2.52$ & 0.001 \\
\hline Worsening RF & 2.53 & $1.80-3.60$ & 0.001 \\
\hline \multicolumn{4}{|l|}{ 1-Year rehospitalization } \\
\hline Noncompliance with medications & 1.05 & $0.86-1.28$ & 0.66 \\
\hline Noncompliance with diet & 1.24 & $0.85-1.80$ & 0.26 \\
\hline ACS & 0.66 & $0.54-0.80$ & 0.001 \\
\hline HTN & 0.86 & $0.67-1.10$ & 0.25 \\
\hline Arrhythmia & 0.93 & $0.71-1.24$ & 0.64 \\
\hline Anemia & 1.01 & $0.70-1.45$ & 0.95 \\
\hline Infection & 0.86 & $0.70-1.06$ & 0.16 \\
\hline Worsening RF & 0.82 & $0.60-1.13$ & 0.23 \\
\hline
\end{tabular}

OR, odds ratio; CI, confidence interval; ACS, acute coronary syndromes; HTN, hypertension; RF, renal function. 
ACS, and infection were associated with higher inhospital mortality (Table 3). Multivariable logistic regression analyses showed that factors significantly associated with increased 1-year mortality include noncompliance with medications, noncompliance with diet, ACS, arrhythmia, anemia, infection, and worsening renal function; HTN was marginally associated with a lower 1-year mortality. There was also a significant association between ACS and a lower rate of 1-year rehospitalization. There were no other significant associations.

\section{Discussion}

This study demonstrated that in a large, prospective, multicenter registry of patients hospitalized for acute HF, PFs contributing to hospitalization were identified in most cases. The prevalence of PFs differed according to the type of acute HF, with noncompliance with medications being the most common in the acute DCHF group and ACS the most common in patients with acute NOHF. Noncompliance with medications was associated with a lower rate of inhospital mortality but with a higher rate of 1-year mortality. In contrast, ACS was associated with higher inhospital and 1-year mortality. Other PFs independently associated with worse outcomes included noncompliance with diet, arrhythmia, anemia, infection, and worsening renal function. On the other hand, uncontrolled HTN as the PF for hospitalization was associated with better outcomes.

Our study found that the most common PF causing decompensation and hospitalization of patients with known HF was noncompliance with medications. In addition, although the early outcome of noncompliance with medications was favorable, it was associated with higher 1-year mortality. Previous studies examining the effects of noncompliance with medications in HF reported favorable early outcomes [16], consistent with our findings. Other studies were either retrospective [17] or followed up small numbers of patients for outcomes [18, 19]. Our study expanded on previous observations in a large, real-world, consecutive patient population hospitalized with acute HF and with 1-year follow up data. The importance of our findings is that they indicate that compliance with medications might prove to be a cost-effective strategy to reduce the mortality burden and cost of HF hospitalizations [20]. In fact, a recent review and meta-analysis by Ruppar et al. [21] found that overall adherence to medication interventions significantly reduced the mortality risk among HF patients and decreased the odds for hospital readmission. Further prospective studies are warranted that focus on which components of medication adherence interventions are most effective in specific HF populations in order to reduce mortality and rehospitalization.

The other major finding of our study is that ACS was the most common PF in patients hospitalized with acute NOHF and associated with increased odds of immediate as well as 1-year mortality. The prognostic impact of HF in patients suffering an ACS has mainly been previously reported in association with short-term mortality [22-24]. Few studies [25-27], apart from ours, have expanded the observation period to include a longer-term postdischarge phase. Additionally, in our study, ACS was associated with lower odds of rehospitalization at 1 year compared to other PFs. We hypothesize that this is due to the fact that when ACS is the reason for acute HF hospitalization, patients undergo revascularization procedures and anti-ischemic therapy that limit further ischemia and thus the need for further rehospitalization.

Worsening renal function in patients hospitalized with acute HF has previously been identified as being associated with worse inhospital and early postdischarge outcomes $[8,28,29]$. Our findings confirm this and demonstrate that acute HF hospitalization precipitated by worsening renal function is also associated with significantly worse patient outcomes, both inhospital as well as 1 year after discharge.

Consistent with previous studies $[6,30]$, infection as a PF for acute HF hospitalization was associated with a higher rate of immediate as well 1-year mortality. Although the reason for higher inhospital mortality from infection is clear, an explanation for how this can affect long-term survival is unknown. Previous studies have shown hospitalization for pneumonia to be an independent risk factor for long-term cardiovascular events [31]. It has been hypothesized [6] that these patients have a weakened immune system, a greater comorbidity burden, and may also suffer from suboptimal medical care and thus have greater long-term morbidity and mortality. On the other hand, HTN as a PF for HF hospitalization was associated with a better prognosis, with lower LOS and lower inhospital and 1-year mortality rates; this is also in agreement with previous studies $[6,8]$.

The main strength of this study is that it was performed prospectively in 47 hospitals in 7 Gulf countries using a well-defined cohort of patients. Documentation of the PFs for acute HF hospitalization was performed prospectively using a standardized approach by the study physi- 
cians who had been following these patients closely. In addition, we included 1-year follow-up data on mortality and rehospitalization outcomes that extend beyond previous studies of PFs for hospitalization for HF that mainly reported inhospital and early postdischarge outcomes.

There are, however, a few limitations in this subanalysis of the Gulf CARE study. Like any observational study, the possibility for unmeasured confounding biases exists. In addition, compliance with medications and diet depended on self-reporting by patients and not on objective measures. Another limitation was that the lack of data from patients discharged directly from the emergency room could have affected the results. Nonetheless, this analysis provides new insights into the factors contributing to HF hospitalizations from a large representative dataset of patients hospitalized for HF and including patients with multiple comorbidities.

\section{Conclusion}

PFs are common in patients hospitalized with acute $\mathrm{HF}$ and vary according to type. Preventive and therapeutic interventions specifically directed at preventable PFs, particularly noncompliance with medications and diet, are warranted.

\section{Acknowledgments}

The Gulf CARE study was an investigator-initiated study conducted under the auspices of the Gulf Heart Association. We thank all the staff at all the participating centers for their invaluable cooperation.

\section{Statement of Ethics}

Ethics approval for this study was obtained from concerned authorities in the recruiting centers. Informed consent was obtained from all patients.

\section{Disclosure Statement}

All authors declare no competing interests. The authors report no relationships that could be construed as a conflict of interest.

\section{Funding Sources}

This study was funded by Servier, Paris, France, and (for centers in Saudi Arabia) the Saudi Heart Association (The Deanship of Scientific Research at King Saud University, Riyadh, Saudi Arabia [Research group No. RG-436-013]). This did not alter our adherence to policies on sharing data and materials and the funders had no role in study design, data collection and analysis, the decision to publish, or preparation of the manuscript.

\section{References}

1 Ambrosy AP, Fonarow GC, Butler J, Chioncel $\mathrm{O}$, Greene SJ, Vaduganathan $\mathrm{M}$, et al. The global health and economic burden of hospitalizations for heart failure: lessons learned from hospitalized heart failure registries. J Am Coll Cardiol. 2014 Apr;63(12):1123-33.

2 Gerber Y, Weston SA, Redfield MM, Chamberlain AM, Manemann SM, Jiang R, et al. A contemporary appraisal of the heart failure epidemic in Olmsted County, Minnesota, 2000 to 2010. JAMA Intern Med. 2015 Jun; 175(6):996-1004

3 Heidenreich PA, Albert NM, Allen LA, Bluemke DA, Butler J, Fonarow GC, et al.; American Heart Association Advocacy Coordinating Committee; Council on Arteriosclerosis, Thrombosis and Vascular Biology; Council on Cardiovascular Radiology and Intervention; Council on Clinical Cardiology; Council on Epidemiology and Prevention; Stroke Council. Forecasting the impact of heart failure in the United States: a policy statement from the American Heart Association. Circ Heart Fail. 2013 May;6(3):60619.

4 Arrigo M, Gayat E, Parenica J, Ishihara S, Zhang J, Choi DJ, et al.; GREAT Network.
Precipitating factors and 90-day outcome of acute heart failure: a report from the intercontinental GREAT registry. Eur J Heart Fail. 2017 Feb;19(2):201-8.

5 Arrigo M, Tolppanen H, Sadoune M, Feliot E, Teixeira A, Laribi S, et al.; GREAT Network. Effect of precipitating factors of acute heart failure on readmission and long-term mortality. ESC Heart Fail. 2016 Jun;3(2):115-21.

6 Berkovitch A, Maor E, Sabbag A, Chernomordik F, Elis A, Arbel Y, et al. Precipitating Factors for Acute Heart Failure Hospitalization and Long-Term Survival. Medicine (Baltimore). 2015 Dec;94(52):e2330.

7 Diaz A, Ciocchini C, Esperatti M, Becerra A, Mainardi S, Farah A. Precipitating factors leading to decompensation of chronic heart failure in the elderly patient in South-American community hospital. J Geriatr Cardiol. 2011 Mar;8(1):12-4.

8 Fonarow GC, Abraham WT, Albert NM, Stough WG, Gheorghiade M, Greenberg BH, et al.; OPTIMIZE-HF Investigators and Hospitals. Factors identified as precipitating hospital admissions for heart failure and clinical outcomes: findings from OPTIMIZE-HF. Arch Intern Med. 2008 Apr;168(8):847-54.
9 Formiga F, Chivite D, Manito N, Casas S, Llopis F, Pujol R. Hospitalization due to acute heart failure. Role of the precipitating factors. Int J Cardiol. 2007 Aug;120(2):237-41.

10 Miró Ò, Aguirre A, Herrero P, Jacob J, Martín-Sánchez FJ, Llorens P; en nombre del grupo ICA-SEMES. [PAPRICA-2 study: role of precipitating factor of an acute heart failure episode on intermediate term prognosis]. Med Clin (Barc). 2015 Nov; 145(9): 385-9.

11 Aguirre Tejedo A, Miró Ò. Precipitating factors in acute heart failure: a review. Emergencias. 2017 Jun;29(3):185-93. Spanish.

12 Sulaiman K, Panduranga P, Al-Zakwani I, Alsheikh-Ali AA, AlHabib KF, Al-Suwaidi J, et al. Clinical characteristics, management, and outcomes of acute heart failure patients: observations from the Gulf acute heart failure registry (Gulf CARE). Eur J Heart Fail. 2015 Apr;17(4):374-84.

13 Sulaiman KJ, Panduranga P, Al-Zakwani I, Alsheikh-Ali A, Al-Habib K, Al-Suwaidi J, et al. Rationale, Design, Methodology and Hospital Characteristics of the First Gulf Acute Heart Failure Registry (Gulf CARE). Heart Views. 2014 Jan;15(1):6-12. 
14 Dickstein K, Cohen-Solal A, Filippatos G, McMurray JJ, Ponikowski P, Poole-Wilson PA, et al; ESC Committee for Practice Guidelines (CPG). ESC Guidelines for the diagnosis and treatment of acute and chronic heart failure 2008: the Task Force for the Diagnosis and Treatment of Acute and Chronic Heart Failure 2008 of the European Society of Cardiology. Developed in collaboration with the Heart Failure Association of the ESC (HFA) and endorsed by the European Society of Intensive Care Medicine (ESICM). Eur Heart J. 2008 Oct;29(19):2388-442.

15 Radford MJ, Arnold JM, Bennett SJ, Cinquegrani MP, Cleland JG, Havranek EP, et al.; American College of Cardiology; American Heart Association Task Force on Clinical Data Standards; American College of Chest Physicians; International Society for Heart and Lung Transplantation; Heart Failure Society of America. ACC/AHA key data elements and definitions for measuring the clinical management and outcomes of patients with chronic heart failure: a report of the American College of Cardiology/American Heart Association Task Force on Clinical Data Standards (Writing Committee to Develop Heart Failure Clinical Data Standards): developed in collaboration with the American College of Chest Physicians and the International Society for Heart and Lung Transplantation: endorsed by the Heart Failure Society of America. Circulation. 2005 Sep;112(12):1888-916.

16 Ambardekar AV, Fonarow GC, Hernandez AF, Pan W, Yancy CW, Krantz MJ; Get With the Guidelines Steering Committee and Hospitals. Characteristics and in-hospital outcomes for nonadherent patients with heart failure: findings from Get with the Guidelines-Heart Failure (GWTG-HF). Am Heart J. 2009 Oct;158(4):644-52.
17 Fitzgerald AA, Powers JD, Ho PM, Maddox TM, Peterson PN, Allen LA, et al. Impact of medication nonadherence on hospitalizations and mortality in heart failure. J Card Fail. 2011 Aug;17(8):664-9.

$18 \mathrm{Wu}$ JR, Moser DK, Chung ML, Lennie TA. Predictors of medication adherence using a multidimensional adherence model in patients with heart failure. J Card Fail. 2008 Sep; 14(7):603-14.

$19 \mathrm{Wu}$ JR, Lennie TA, De Jong MJ, Frazier SK, Heo S, Chung ML, et al. Medication adherence is a mediator of the relationship between ethnicity and event-free survival in patients with heart failure. J Card Fail. 2010 Feb;16(2):142-9.

20 Ho PM, Bryson CL, Rumsfeld JS. Medication adherence: its importance in cardiovascular outcomes. Circulation. 2009 Jun;119(23):3028-35.

21 Ruppar TM, Cooper PS, Mehr DR, Delgado JM, Dunbar-Jacob JM. Medication Adherence Interventions Improve Heart Failure Mortality and Readmission Rates: Systematic Review and Meta-Analysis of Controlled Trials. J Am Heart Assoc. 2016 Jun;5(6):e002606.

22 Alsheikh-Ali AA, Al-Mallah MH, Al-Mahmeed W, Albustani N, Al Suwaidi J, Sulaiman $\mathrm{K}$, et al.; Gulf RACE Investigators. Heart failure in patients hospitalized with acute coronary syndromes: observations from the Gulf Registry of Acute Coronary Events (Gulf RACE). Eur J Heart Fail. 2009 Dec;11(12):1135-42.

23 Steg PG, Dabbous OH, Feldman LJ, CohenSolal A, Aumont MC, López-Sendón J, et al.; Global Registry of Acute Coronary Events Investigators. Determinants and prognostic impact of heart failure complicating acute coronary syndromes: observations from the Global Registry of Acute Coronary Events (GRACE) Circulation. 2004 Feb;109(4):494-9.

24 Velazquez EJ, Francis GS, Armstrong PW, Aylward PE, Diaz R, O'Connor CM, et al.; VALIANT registry. An international perspective on heart failure and left ventricular systolic dysfunction complicating myocardial infarction: the VALIANT registry. Eur Heart J. 2004 Nov;25(21):1911-9.
25 Kaul P, Ezekowitz JA, Armstrong PW, Leung BK, Savu A, Welsh RC, et al. Incidence of heart failure and mortality after acute coronary syndromes. Am Heart J. 2013 Mar; 165(3):379-85.e2.

26 Berton G, Cordiano R, Cavuto F, Bagato F, Pellegrinet M, Cati A. Heart failure in women and men during acute coronary syndrome and long-term cardiovascular mortality (the ABC-3* Study on Heart Disease) (*Adria, Bassano, Conegliano, and Padova Hospitals). Int J Cardiol. 2016 Oct;220:53843.

27 Sulo G, Igland J, Nygård O, Vollset SE, Ebbing $\mathrm{M}$, Poulter N, et al. Prognostic Impact of InHospital and Postdischarge Heart Failure in Patients With Acute Myocardial Infarction: A Nationwide Analysis Using Data From the Cardiovascular Disease in Norway (CVDNOR) Project. J Am Heart Assoc. 2017 Mar; 6(3):6.

28 Forman DE, Butler J, Wang Y, Abraham WT, O'Connor CM, Gottlieb SS, et al. Incidence, predictors at admission, and impact of worsening renal function among patients hospitalized with heart failure. J Am Coll Cardiol. 2004 Jan;43(1):61-7.

29 Gottlieb SS, Abraham W, Butler J, Forman $\mathrm{DE}$, Loh E, Massie BM, et al. The prognostic importance of different definitions of worsening renal function in congestive heart failure. J Card Fail. 2002 Jun;8(3):136-41.

30 Alon D, Stein GY, Korenfeld R, Fuchs S. Predictors and outcomes of infection-related hospital admissions of heart failure patients. PLoS One. 2013 Aug;8(8):e72476.

31 Yende S, Angus DC, Ali IS, Somes G, Newman $A B$, Bauer $D$, et al. Influence of comorbid conditions on long-term mortality after pneumonia in older people. J Am Geriatr Soc. 2007 Apr;55(4):518-25. 